\title{
EFFECT OF DIFFERENT NANOFLUIDS ON PERFORMANCE OF SHELL AND TUBE HEAT EXCHANGER: A REVIEW
}

\author{
Swapnil S. Kamthe ${ }^{1}$, Shivprakash B. Barve ${ }^{2}$ \\ ${ }^{1}$ Post graduate student, Department of Mechanical Engineering, MAEER's MITCOE, Pune 411038, Maharashtra \\ ${ }^{2}$ Professor, Department of Mechanical Engineering, MAEER's MITCOE, Pune 411038, Maharashtra, India
}

\begin{abstract}
Shell and tube heat exchanger is widely used in many application. Increased performance and efficiency are the most demanding need in today's world. Working fluid like nanofluid with high heat transfer coefficient can be a promising alternative to the existing system. Itshould possess the height thermal conductivity, low viscosity, high specific heat, and stability. This paper discusses the review work on the uses of the nanofluid to increase the performance of shell and tube heat exchanger. The effect of different material with different base fluid has been presented with different nanoparticle shape on the performance of exchanger and on the thermal properties of working fluid has been presented. Some of the literature shows contradictory results it is concluded that the combination of $\mathrm{ZnO}$ and $\mathrm{W}$ nanofluid gives the best performance among other which has presented due to its high thermal conductivity and low viscosity. Turbulence region shows best result compare with laminar and high-pressure drop compared with it. Cylinder shape shows the better performance among considered shapes in literature. Nanoparticle should be suspended in base fluid for the long term uses which is the biggest limitation of it in a real-time application.
\end{abstract}

Keywords: Concentration, Heat transfer coefficient, Nanofluid, Pressure drop and Shell and tube heat exchanger etc.

\section{INTRODUCTION}

In heat exchanger heat is transfer from the higher to lower temperature difference and transfer of heat is an important aspect of the heat transfer application. In shell and tube one fluid is passed through shell and one through shell. The efficiency is depending upon the amount of transfer heat and mode of heat transfer. Heat is transfer from hot to cold fluid through wall max heat can transfer based on the heat transfer coefficient of transferring medium and the thermal conductivity of material. Effectiveness shows the capability of maximum heat transfer for a given area. Increase in efficiency and effectiveness are the great concern in today's scenario. To increase efficiency heat transfer between small temperature should be increased this can be done by increasing the efficiency of the working fluid. Efficient fluid possesses properties like high convection coefficient on which the heat transfer of fluid is depend, low viscosity and high thermal conductivity. Number of experimental investigation has been done on the enhancement of the thermal properties of working fluid $[1,2]$.

In heat exchanger working fluids main property for the heat transfer application as convection coefficient depends upon the thermal conductivity of that particular material. Number of research's done to increase the conductivity by using additions of some additives in it [1].

Research also available for increase in heat transfer coefficient with minimum pressure drop for different baffles [3]. Suspended material particle having high conductivity in fluid is one of the enhancement technique. There are two types of particles are there like micro scale and nano scale. Micro scale particle having limitation like suspension problem and clogging of flow channel. Particle can be metallic or non-metallic depends upon its application and property. Nanoparticle size particle is first studied by Argonne National Laboratory [4]. Nanoparticle have better thermos physical property than micro sized particle use of it in heat transfer application would be a great advantage. Generally, it having size $100 \mathrm{~nm}$ below of it [5]. Fluid which contain nano sized particle in it is called as nanofluid, due to its properties it enhanced the property of base fluid also overcome the clogging effect. If we compare it with conventional fluid it having high surface area and better thermal properties. Keblinski presented the review of nanofluids properties and its future challenges, due to its ability to suspend and stability in liquid it can be a promising way to use in heat transfer application [6]. In this paper, different nanofluids are reviewed based on literature and available data and its use in shell and tube heat exchanger specifically, also effect of different parameter on performance of fluid.

\section{DIFFERENT NANOFLUIDS}

In this different nanoparticle materials review is done separately. Nanofluid with same material and different base fluid can have different property based on base fluid.

\subsection{Aluminum Oxide}

Aluminum oxide $\left(\mathrm{Al}_{2} \mathrm{O}_{3}\right)$ having density $3690 \mathrm{~kg} / \mathrm{m}^{3}$ and specific heat of $880 \mathrm{~J} / \mathrm{kg} \mathrm{k}$. different study are available on the use of this in shell and tube exchanger. One of this presented by Ramtin Barzegarian. In this base fluid as a water is used. Experimental investigation is done with segmentally operated baffle in heat exchanger.15 $\mathrm{nm}$ and 
99.5\% purity type of particle has used with the Sodium Dodecyl Benzene Sulphonate (SDBS) as surfactant. Nanofluid prepaid with the volume fraction of 0.03,0.14 and 0.3. Performance parameter considered are Reynolds number, volume concentration, friction factor and thermal performance factor for heat exchanger. All are considered in laminar zone. The outcome shows that the overall coefficient can be increased by increasing Reynolds number and with increasing the concentration of nanoparticle about a $29.8 \%$ for $0.3 \%$. And $18.9 \%$ increase in thermal performance factor [7]. Small pressure drop penalty is observed in experimentation.

I.M. Shahrul also presented work on same nanofluid and presented result as compared with water and also the effect of flow rate of both the side of fluid on performance of exchanger. nanofluid flowing through the tubes and shell side is water [8]. About $26 \%$ increment in overall coefficient has found out compared with water and at $7 \mathrm{lpm}$ highest performance is showed, considered fraction is $0.5 \%$.

B. Farajollahi done work on same fluid but in turbulent region. Considered volume fractions are $0.3 \%, 0.5 \%, 0.75 \%$, $1 \%$ and $2 \%$. At $0.5 \%$ fraction, maximum improvement in overall coefficient $20 \%$ has shown [9].

\subsection{Graphene Oxide}

Milad Rabbani Esfahani has done the experimental work on this nano particle to find the effect on exergy of exchanger. Particle concentration used as $0.01 \%$ and $0.1 \%$. By using transient hot wire method thermal conductivity of nanofluid has measured at 25 and $40^{\circ} \mathrm{C} .8 .7 \%$ and $18.9 \%$ increase in thermal conductivity for $0.01 \%$ and $0.1 \%$ wt concentration resp. compared with water less exergy loss had observed in laminar as well as turbulent flow condition. Result also showed that with increasing concentration viscosity is also increase. It has also noticed that with increasing the hot fluid temperature exergy loss increases due to the large temperature difference between hot and cold fluid [10].

Ahmad Ghozatloo has studied the effect of this particle on convective heat coefficient of exchanger under laminar flow condition. About a $0.075 \mathrm{wt} \%$ addition of particle increases thermal conductivity up to $31.38 \%$ compared with water, it also shows that thermal conductivity is the strong function of stability of nano particle in base fluid. Temperature increase of 25 to $38^{\circ}$ increase convective coefficient up to $13.1 \%$ for $0.1 \%$ wtfraction. Athigher temperatures, the effect of graphene concentration in water is more noticeable. By increase of concentration of graphene from $0.025 \%$ to $0.1 \%$ wt, $15.3 \%$ Increment in heat coefficient was observed at $25^{\circ} \mathrm{C}$, at $38^{\circ} \mathrm{C}$, increment of $23.9 \%$ in heat coefficient was notedat $25^{\circ} \mathrm{C}[11]$.

\subsection{Zinc Oxide}

I.M. Shahrul studied the effect of zinc oxide nano particle on the performance of working fluid in exchanger. For the stabilization of zinc polyvinylpyrrolidone (PVP) surfactant has used, for justification of this photo capturing method is used. Results showed that about $35 \%$ increment in overall heat coefficient has observed. Also, the effect of flow rate is demonstrated here, maximum performance get at $6 \mathrm{lpm}$ of tube flow and $8 \mathrm{lpm}$ of shell flow. The reason behind this can be say that due to the high thermal conductivity and low viscosity which promote browning motion result in improved performance.

\subsection{Silicon Dioxide}

Silicon dioxide can also be used in heat transfer application for shell and tube no detail literature is available. I.M. Shahrul studied the effect of silicon dioxidenano particle on the performance of working fluid in exchanger.0.5 vol \% is used for examination purpose with 90 min of ultrasonication process. Results showed that about $12 \%$ increment in overall heat coefficient has observed. Also, the effect of flow rate is demonstrated here, maximum performance get at $7 \mathrm{lpm}$ of tube flow and $8 \mathrm{lpm}$ of shell flow. The reason behind this can be say be that browning motion result in improved performance. If we compare with other nanofluid it is showing low enhancement in heat exchanger performance.

KanjirakatAnoop done work on experimental investigation on shell and tube by using $\mathrm{Sio}_{2} / \mathrm{W}$ nanofluid. $20 \mathrm{~nm}$ size is used in work with wt concentration of $2 \%, 4 \%$ and $6 \%$. Maximum enhancement is found to be7 $\%$ at $4 \%$. To overcome the viscosity $6 \%$ pressure drop has found in work [12].

\subsection{Ferric Oxide}

Nishant Kumar presented work on ferric oxide and water and ethylene glycol as a base fluid. Heat transfer performance is measured under laminar to turbulent flow region. Concentrations used are $0.02 \%, 0.04 \%, 0.06 \%$ and $0.08 \%$ vol. It has observed that addition of nanoparticle improves performance of base fluid. Water based fluid shows best compared to ethylene glycol due to its thermophyscal properties [13].

Mohammad Hossein also done work on ferric oxide and carbon nanotube hybrid nano fluid. First time ever hybrid nanofluid is prepare by author. Three flow regions has considered like laminar, transient and turbulent flow. Size of nanoparticle is $30 \mathrm{~nm}$ with water as a base fluid. $0.1 \%$ and $0.2 \%$ wt concentration has used. Results revealed that for $0.1 \%$ wtconcentration heat coefficient was enhanced $13.54 \%$ and $27.69 \%$ for the laminar and turbulent flow. Also at $0.2 \%$ weightconcentration for laminar and turbulent flow enhanced $34.02 \%$ and $37.50 \%$ in comparison withdistilled water.The highest heat coefficient enhancement is $27.69 \%$ in $0.1 \mathrm{wt} . \%$ and $48.19 \%$ in $0.2 \mathrm{wt} . \%$ [14].

\subsection{Carbon Nano Tubes}

S. Masoud Hosseini has done work on CNT with volume fraction of $0.0055 \%, 0.055 \%, 0.111 \%$ and $0.278 \%$. Performance of heat exchanger simulated by ASPEN HTFS7.3 software. For max vol concentration $14.5 \%$ \& $10.3 \%$ increase in overall heat coefficient and heat rate respectively. 
Temperature of hot fluid at outlet get decreased with increasing and addition of nano particle compared with water. Heat transfer can also increase with increase in mass flow rate. Due to the low fraction pumping power is very small can be neglected [15].

\section{EFFECT OF PARAMETERS}

In this section effect of different parametric condition on thermal conductivity of nanofluid which indirectly affect the thermal performance of heat exchanger is reviewed.

\subsection{Temperature}

Increase in temperature of nanofluid increases the thermal conductivity of fluid. Which increase the energy in particle start to move in fast manner indirectly increases the turbulence. Particle near the wall gets energy and move in random manner which collide each other transfer energy. This type of motion is responsible to get increased conductivity. Due to temperature viscosity also get reduced which also reduce pressure drop and particle move faster in stream. Efficiency of the heat exchanger also get increased.

\subsection{Particle Concentration}

Small amount of nanoparticle in base fluid significantly increase the thermal conductivity of base fluid. If we increase the concentration density of fluid get increased with increase in particle density and due to its thermal conductivity get increases but pressure drop also increase with increase in viscosity. With particle concentration, fast interaction between particle takes place due to which fast energy exchange takes place and efficiency of fluid to transmit heat gets increases, after particular limit thermal conductivity start to decrease due to the increased viscosity which affect the motion of particle in fluid and eventually increase in pressure drop. For each nanofluid there will be optimum value of concentration, generally small mean dia of nano particle having small optimum concentration range.

\subsection{Shape of Particle}

Most commonly use particles in nanofluids are spherical, rod, tube and disk-shaped nanoparticles. Some of Nano particle may form cluster have fractal like shape. M.M. Elias studied the cylindrical, bricks, blades, and platelets types of nanoparticles and result shows that cylindrical type of nano particle shows best compared to others [16]. Shape of particle have direct impact on thermal conductivity of fluid. Cylindrical shape having high surface to volume ratio compare to others due to which it gives best performance. Hassan Hajabdollahi also study the same four types of shape of nano particle. Higher particle concentration was needed in the cases of blades and bricks nanoparticle shapes. In this also cylindrical shows the best result [17].

\subsection{Flow Rate}

Flow rate have indirect impact on thermal conductivity of nanofluid. In fluid without Nano additives heat transfer increase with increase in flow rate due to the increase in intensity of turbulence and energy exchange process. With addition of Nano additives increase in flow rate increase turbulence in flow which accelerate the movement of particle through fluid. Browning motion gets accelerated near wall or contact area. But after some fixed value thermal conductivity gets decreased due to the no enough time it will get for transfer of heat. For each nanofluid there will be one optimum value of flow rate in shell and tube heat exchanger.

Table -1: Comparative results

\begin{tabular}{|c|c|c|}
\hline Nanofluid & Fraction & HTC improvement \\
\hline $\begin{array}{l}\Upsilon-\mathrm{Al}_{2} \mathrm{O}_{3}-\mathrm{W} \\
\text { and } \mathrm{Tio}_{2}-\mathrm{W}\end{array}$ & $\begin{array}{l}(0.3,0.75,1,2 \%) \\
\text { and } \\
(0.15,0.3,0.5,0.7 \\
5 \%)(\text { vol. } \%)\end{array}$ & $\begin{array}{l}\text { i. } 46 \%, 56 \%, 46 \% \text {, } \\
38 \% \text {, and } 19 \% \\
\text { ii. } 20 \%, 56 \%, 33 \% \text {, } \\
\text { and } 18 \%\end{array}$ \\
\hline $\begin{array}{l}\mathrm{ZnO}-\mathrm{W}, \\
\mathrm{Al}_{2} \mathrm{O}_{3}-\mathrm{W} \\
\text { and } \mathrm{SiO}_{2}-\mathrm{W}\end{array}$ & $\begin{array}{l}0.3 \% \\
0.5 \%, 0.5 \% \\
\text { (vol.\%) resp. }\end{array}$ & $50 \%, 15 \%$ and $9 \%$ \\
\hline $\begin{array}{l}\mathrm{Fe}_{2} \mathrm{O}_{3} / \text { water } \\
\text { and } \\
\mathrm{Fe}_{2} \mathrm{O}_{3} / \mathrm{EG}\end{array}$ & $\begin{array}{l}0.02,0.04,0.06 \\
\text { and } 0.08 \text { vol. } \% \\
\text { each }\end{array}$ & $\begin{array}{l}\text { i. } 13 \%, 15 \%, 17 \% \text { and } \\
20 \% \\
\text { ii. } 5 \%, 8 \%, 10 \% \text { and } \\
13 \%\end{array}$ \\
\hline $\begin{array}{l}\mathrm{Fe}_{2} \mathrm{O}_{3-} \\
\text { CNT/water }\end{array}$ & 0.1 and 0.2 & $\begin{array}{l}\text { i. } 27.69 \% \\
\text { ii. } 37.50 \%\end{array}$ \\
\hline $\mathrm{Y}-\mathrm{Al}_{2} \mathrm{O}_{3}$ & $\begin{array}{l}0.03,0.14 \text { and } \\
0.3 \% \text { vol }\end{array}$ & $5.4,10.3$ and $19.1 \%$ \\
\hline $\begin{array}{l}\text { graphene } \\
\text { oxide }\end{array}$ & $\begin{array}{l}0.05,0.075 \text { and } \\
0.1 \text { wt } \%\end{array}$ & $8.2,17.1$ and $27.2 \%$ \\
\hline $\mathrm{TiO}_{2}$ & $\begin{array}{l}0.07 \%, 0.14 \% \\
\text { and } 0.21 \% . \mathrm{vol}\end{array}$ & $5.5 \%, 7.8 \%$ and $11.2 \%$ \\
\hline $\mathrm{Al}_{2} \mathrm{O}_{3}$ & 2 and $4 \%$ & 8 and $13 \%$, \\
\hline
\end{tabular}

\section{CONCLUSION}

This paper work presents the over review of research's done till today.

1. It can be concluded that due to addition of nanofluid in base fluid will improve heat transfer characteristics of base fluid.

2. Addition of nanofluid increases heat transfer area compared with base fluid which directly increases heat transfer and indirectly heat coefficient of heat exchanger. Due to the presence of the nano particle near the wall hence fast heat transfer takes place.

3. Increase in nanoparticle concentration increase thermal conductivity of base fluid due to the availability of particle for energy exchange. Which also leads to increase turbulence level in fluid which directly speed up energy exchange process.

4. Pressure drop in laminar flow is less compared with turbulent flow. In laminar flow, less pressure drop occurs. For each type of nanofluid there will be optimum concentration at which more heat transfer and less flow resistance occurs in different flow regions which depends on the properties of nanofluid.

5. $\mathrm{ZnO}-\mathrm{W}$ (with polyvinylpyrrolidone (PVP)) nanofluid gives best performance among all nanofluids considered in literature about an $35 \%$ compared with water $(6 \mathrm{lpm}$ tube side).

6. Less optimum concentration found for particle having less mean diameter. 


\section{ACKNOWLEDGEMENT}

I am very thankful to Prof. (Dr.) S B. Barve for guiding and supporting me in preparing this paper.

\section{REFERENCES}

[1]. B. Farajollahi, S.G. Etemad, M. Hojjat, Heat transfer of nanofluids in a shell and tube 4Q2611 heat exchanger, Int. J. Heat Mass Transf. 53 (2010) 12-17.

[2]. N. Kumar, S.S. Sonawane, Experimental study of thermal conductivity and convective heat transfer enhancement using $\mathrm{CuO}$ and $\mathrm{TiO}_{2}$ nanoparticles, Int. Heat Mass Transfer 76 (2016) 98-107.

[3]. Swapnil S. Kamthe, Shivprakash B. Barve, Effect of Different types of Baffles on Heat Transfer \& Pressure Drop of Shell and Tube Heat Exchanger: A review, International Journal of Current Engineering and Technology, E-ISSN 2277 - 4106, P-ISSN 2347 - 5161.

[4]. U.S. Choi, Enhancing thermal conductivity of fluids with nanoparticles, ASME FED 431231 (1995) 99-103.

[5]. E.F. Dilek, Preparation of Nano-Fluid and Determination of Thermal Conductivity. 433(Master's Thesis) Atatürk University, 2009.

[6]. P.Keblinski, J.A. Eastman, D.G. Cahill, Nanofluids for thermal transport, Mater. Today 4Q40128 (6) (2005) 36-44.

[7]. Ramtin Barzegariana, Alireza Aloueyanb, Tooraj Yousefic, Thermal performance augmentation using water based $\mathrm{Al}_{2} \mathrm{O}_{3}$-gammananofluid in a horizontal shell and tube heat exchanger under forced circulation, International Communications in Heat and Mass Transfer 86 (2017) 5259.

[8]. I.M. Shahrul, I.M. Mahbubul, R. Saidur, M.F.M. Sabri, Experimental investigation on $\mathrm{Al}_{2} \mathrm{O}_{3}-\mathrm{W}, \mathrm{SiO}_{2}-\mathrm{W}$ and $\mathrm{ZnO}-$ $\mathrm{W}$ nanofluids and their application in a shell and tube heat exchanger, International Journal of Heat and Mass Transfer 97 (2016) 547-558.

[9]. B. Farajollahi, S.Gh. Etemad, M. Hojjat, Heat transfer of nanofluids in a shell and tube heat exchanger, International Journal of Heat and Mass Transfer 53 (2010) 12-17.

[10]. Milad Rabbani Esfahani, Ehsan Mohsenianguri, Exergy analysis of a shell-and-tube heat exchanger using graphene oxide nanofluids, S0894-1777(16)30360-0.

[11]. Ahmad Ghozatloo, Alimorad Rashidi, Mojtaba Shariaty-Niassar, Convective heat transfer enhancement of graphene nanofluids in shell and tube heat exchanger, S0894-1777(13)00272-0.

[12]. Kanjirakat Anoop, Jonathan Cox, Reza Sadr, Thermal evaluation of nanofluids in heat exchangers, International Communications in Heat and Mass Transfer 49 (2013) 5-9.

[13]. Nishant Kumar, Shriram S. Sonawane, Experimental study of $\mathrm{Fe}_{2} \mathrm{O}_{3}$ /water and $\mathrm{Fe}_{2} \mathrm{O}_{3}$ /ethylene glycol nanofluid heat transfer enhancement in a shell and tube heat exchanger, International Communications in Heat and Mass Transfer (2016).

[14]. Mohammad Hossein Aghabozorg, Alimorad Rashidi, Saber Mohammadi, Experimental investigation of heat transfer enhancement of Fe2O3-CNT/water magnetic nanofluids under laminar, transient and turbulent flow inside a horizontal shell and tube heat exchanger,S08941777(15)00334-9.

[15]. S. Masoud Hosseini, Leila Vafajoo, B.H. Salman, Performance of CNT-water nanofluid as coolant fluid in shell and tube intercooler of a LPG absorber tower, International Journal of Heat and Mass Transfer 102 (2016) 45-53.

[16]. M.M. Elias, I.M. Shahrul, I.M. Mahbubul, R. Saidur, N.A. Rahim, Effect of different nanoparticle shapes on shell and tube heat exchanger using different baffle angles and operated with nanofluid, International Journal of Heat and Mass Transfer 70 (2014) 289-297.

[17]. Hassan Hajabdollahi, Zahra Hajabdollahi, Numerical Study on Impact Behavior of Nanoparticle Shapes on the Performance Improvement of Shell and Tube Heat Exchanger,S0263-8762(17)30284-8.

\section{BIOGRAPHIES}

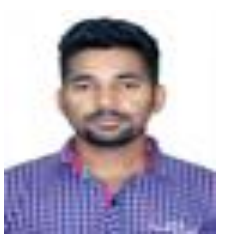

Swapnil S. Kamthe, Pursuing M.E (Mechanical Engineering) Heat Power. Completed B.E Pune University.

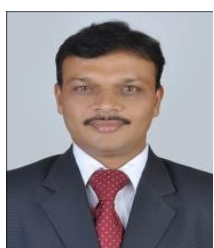

Dr. Shivprakash B. Barve, Ph. D. (Mechanical Engineering), Experience of 20 Years in Teaching. Author of 65 Research papers and three text books. 